\title{
Clinical EducATion: A UnIVERSITY OF DURBan-WestVILLE CASE STUDY
}

\begin{abstract}
Clinical education has been recognised as an important component of the undergraduate physiotherapy programme. As such it has received considerable attention in the literature. However the aspect of offering this component effectively to large numbers of students has not been addressed. The purpose of this retrospective study was to analyse and compare both quantitatively and qualitatively the effects of one highly structured and three semistructured models of clinical education using a 12 to 1 student: clinical instructor ratio. The study population consisted of the 1999 third year class of 39 students who were clinically supervised by four lecturers. The students' block

NADASAN T (B. Physio, DOT, HED, M. Physio)'; PUCKREE T (BSc Physio, M. ED, MS, PhD/2

${ }^{1}$ Lecturer, Department of Physiotherapy, University of Durban-Westville.

2 Senior Lecturer, Department of Physiotherapy, University of Durban-Westville. marks as well as their subjective impressions were analysed and summarized respectively. The results show that there were no significant differences between structured and semi-structured models. In addition a 12: I student: clinical instructor ratio can produce good clinical education outcomes.
\end{abstract}

\section{KEY WORDS: CLINICAL EDUCATION, STUDENT: CLINICALINSTRUCTOR RATIO, STUDENT PERFORMANCE, STUDENT IMPRESSIONS}

\section{INTRODUCTION}

Clinical education is an important component of the learning strategies used to optimize clinical competence in undergraduate physiotherapy students (Tiberius and Gaiptman, 1985; Ladyshewsky, 1993; De Clute and Ladyshewsky, 1993). De Clute and Ladyshewsky (1993) suggest that the quality of future health care is dependent on well-developed clinical education programmes. The latter is dependent on available facilities which include the variety of affiliating sites as well as a variety of patients at these sites, the number of students to be educated, the number of support and tutoring clinical and academic staff.

Literature from clinical educators in several parts of the world (De Clute and Ladyshewsky, 1993; Tiberius and Gaiptman, 1985) suggests a 1:1 student

\section{CORRESPONDENCE TO:}

T Puckree

Private Bag X54001

Durban 4000

Tel: (031) 204-4977/204-4817 (w)

(031) 204-4817 (h)

Fax:(031) 204-4817

Email: 1puckree@pixie.udw.ac.za instructor ratio to obtain the best learning outcomes. However, due to staff shortages, and decreased experience levels in available clinical staff, 2:1 (De Clute and Ladyshewsky, 1993; Ladyshewsky, 1993; Lopopolo, 1984; Grandy, 1988) and 3:1 (Emery, 1986) student : clinical instructor ratios have been suggested and implemented in developed countries such as the United States of America. The benefits of the 2: I ratio include financial benefits, the benefit to staff shortages by increasing the productivity of the team (Lopopolo, 1984), peer support system for students (Gandy, 1988), and increased student placements in particular affiliations (Lopopolo, 1984; Gandy, 1988).

The University of Durban Westville is one of eight Physiotherapy training centres in South Africa. To meet the physiotherapy needs of the province which has severe staff shortages the school had to increase its intake from approximately 15 students in the first year prior to 1996 to approximately 40 thereafter. The academic staff compliment however increased from about seven to ten in the same period. The school offers clinical education, which starts in the second year of the programme and continues up to the 4th year of the four-year programme. This implies that at any one point in time approximately 120 students are in clinical placements, only within the greater Durban area. The clinical education of these students has had to be distributed amongst the 10 members of staff, which effectively produces a student: clinical instructor ratio of $12: 1$. The structure of the provincial health care system with its staff shortages offers minimal help from clinical physiotherapists placing the entire burden of clinical education on the academic physiotherapists.

The purpose of this retrospective study was to determine strategies used to cope with the large student: clinical instructor ratio to ensure optimal clinical education. The following issues were questioned as points of departure:

1. Did a structured organization of the clinical experience influence the learning outcomes with this unusually high student: clinical instructor ratio?

2. What were the students perceptions of their clinical block?

\section{METHODS:}

The population for this critical analysis consisted of 39 third year students who rotated through four clinical blocks namely, subacute and chronic facility 
(mostly burns, neurology, pediatrics, orthopedics - block 1); acute facility (all conditions with a short hospital stay of less than three days - block 2); community (block 3); and facility catering for conditions complicating from tuberculosis and spinal cord injuries (adult and pediatrics - block 4), in 1999. There were essentially three groups of ten and one group of nine students in any particular block at a time block, which lasted six weeks. An academic staff member was responsible for each block.

A semi-structured format for clinical education existed but each academic supervisor followed his or her own format. A clinical education workshop was carried out by the academic supervisors for each group of students in all four clinical areas before commencing the clinical education programme. In addition all students were given a clinical record book containing information on the clinical programme, departmental regulations, general and specific guidelines and objectives for all four clinical areas, lists of conditions to be seen /treated, time schedules to record clinical hours and the assessment forms. To answer our questions a structured format was applied in block 4 .

The format followed for block 4 were as follows:

The academic supervisor met with the clinical person in charge of the facility before the commencement of each block. This allowed the supervisor to compile a list of patients to be treated by students, to organise a student register, theatre and $\mathrm{x}$-ray visits and to assist with monitoring of student attendance and professional behavior.

On the first day of the block the academic supervisor discussed the specific guidelines and objectives, record keeping and assessments with the students. In addition a separate handout on guidelines of weekly student expectations were given and discussed.

Week 1: Students were given individual supervision/guidance with assessing and writing up of patient assessments and treatments. Students were requested to hand in their written assessments for marking each Friday morning. Feedback was given to students on an individual basis. Group discussions and tutorials were also held. Students working in pairs were assigned a case study patient which entailed an in-depth study of the condition, detailed assessment, daily progress reports, overall management in all stages of rehabilitation, consultation with the family, other health care professionals and presentation (written and treatment).

Week 2: Students were given individual supervision and presented patients to the supervisor only. Clinical hours, performance of assessment/treatment techniques (indicated as good or needs improvement) and conditions seen/ treated were recorded in all students' clinical books. Feedback was given to students on an individual basis as well as collectively, summarizing common problems.

Week 3: Students presented their patients individually to the supervisor and the rest of the group. Students were encouraged to constructively criticize the presentation. Continuous evaluation and updating of the clinical record book (as above) was carried out for all students.

Week 4: Each student was examined on their competent use of therapeutic procedures for 30 minutes. The clinical record book was updated. Feedback was given to students on an individual basis. Common problems were discussed and clarified.

Week 5: Students worked in pairs to present the case study patient to the supervisor and the rest of the students. The rest of the students constructively criticized and made suggestions to the presentation. The record book was again updated.

Week 6: Remedial work was undertaken to rectify deficits in cognitive, affective and psychomotor skills. The supervisor completed the continuous evaluation forms for all students. This entailed looking at each student's portfolio of all patient assessments, treatments, progress reports, case study, other additional information collected on their patients, all their previous presentations (individually to the supervisor as well as to the group) and feedback from the clinical head of department on professional aspects. Students evaluated the block reflecting on their clinical education and experience. They also highlighted the strengths and weaknesses of the experience and suggested possible solutions.

The following points were also emphasized:

Every Friday morning three students watched operations in theatre. The students also signed the register, entered patient names in the list book and made recordings in the clinical book daily. Students spent two hours on $x$-ray interpretation sessions carried out by a radiologist.

There was a gradual increase in patient load initially. Thereafter students had to have at least 5 or more patients at all times. Continuous assessment occurred throughout the block. Students had to notify the supervisor when additional tutorials were required on specific problem areas. Additional reading on the clinical conditions was compulsory.

Students had to cover their clinical hours in the case of absences.

\section{Student Evaluations:}

The final end of block mark consisted of the continuous assessment, which made up $50 \%$ of the mark. A formal examination of a therapeutic procedure by the supervisor made up the other $50 \%$. This was similar for the structured and unstructured clinical education models.

\section{Data Analysis:}

The performance of each student in each block was tabulated as a percentage change of their performance in the first block and compared across blocks and with the performance in the last block for the year. Student t-tests were used to determine statistical significance with a probability of 0.05 . The subjective impressions of the students were summarized in broad categories.

\section{RESULTS:}

As shown in Figure 1 there was no significant difference in the performance of students in the different blocks regardless of whether they were structured or not. However the subjective impressions of the student are summarized in the following section. 
Figure legends:

Figure 1: Percentage change in student performance in each of the four clinical blocks and clinical rotations. The numbers at the top of each bar represents the block in which the students were at a particular time. Student group 1 started in block four, proceeded to block 3 , then block 2 then block 1 . Student group 2 rotated from block 1 to block 4 to block 3 to block 2 . Student group 3 rotated from block 2 to block 1 to block 4 to block 3. Student group 4 rotated from block 3 to block 2 to block 1 to block 4 .

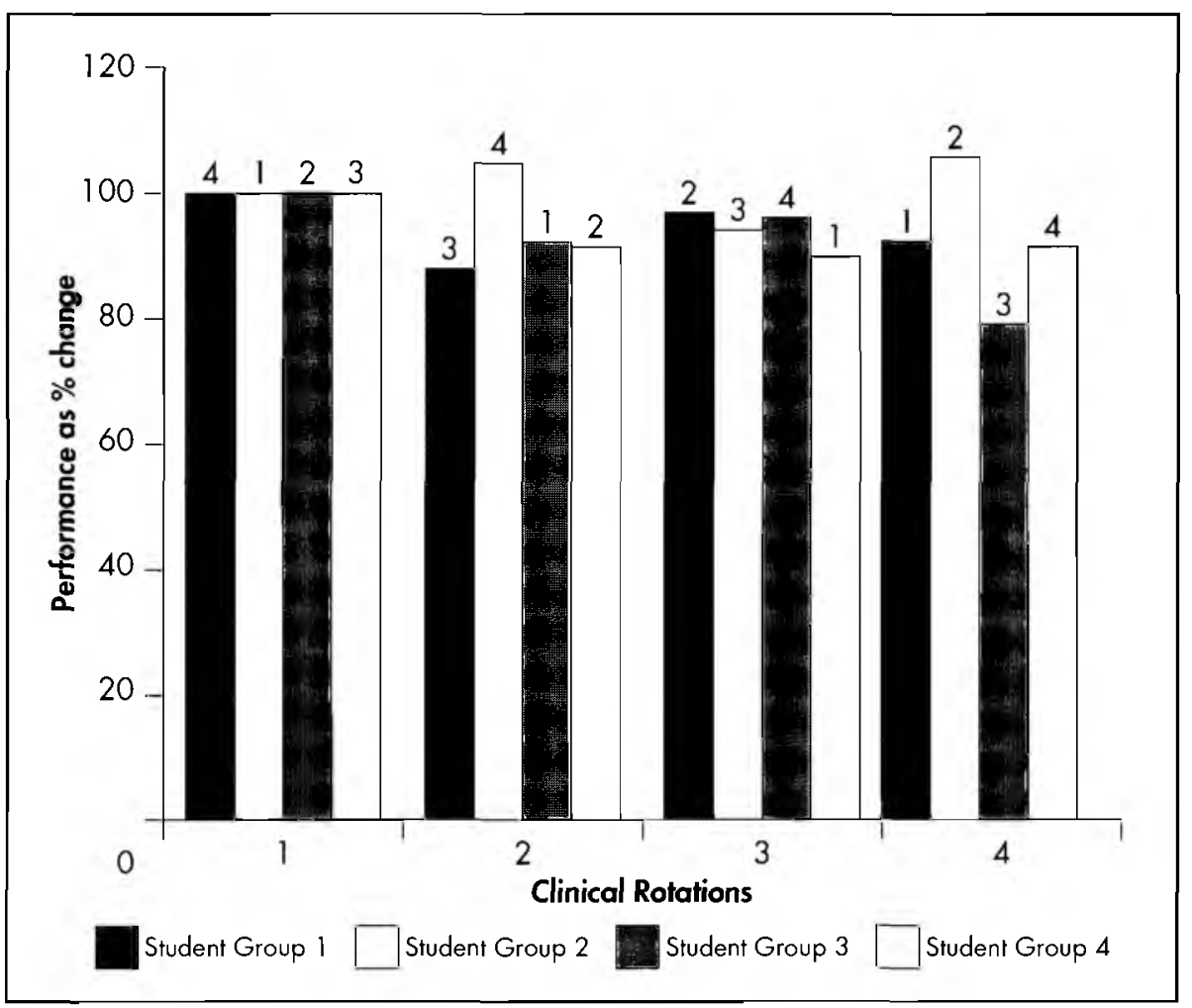

A subjective assessment was done by all four groups of students for block 4 in order to obtain their impressions about their clinical experience. Students had to comment constructively on the block by identifying the strengths, weaknesses and possible solutions.

\section{Exposure:}

The students felt that the facilities for clinical education in terms of patient variety and supervisors were adequate. However they also felt that the gymnasium was too small to accommodate more than 10 students and their patients. This therefore resulted in the equipment being inadequate to meet the needs of all students. The students felt that if the use of the gymnasium was scheduled to prevent overcrowding, then all students would have the opportunity to use all types of equipment and rehabilitate their patients optimally. The staff was friendly and helpful and gave good advice.

Students felt that exposure to see surgical procedures allowed for a clearer their ability to integrate information, allowed for peer evaluation and cognitive, affective and psychomotor learning. On the negative side, it was time consuming especially when academic facilities like the library were inadequate. Exposure to a variety of patients would have enhanced this mode of learning.

The record book was well formulated, user friendly and provided adequate guidelines for clinical education throughout the block. It also allowed for students to easily record their clinical hours.

The presentation format included individual student to lecturer only, individual to group of students and supervisors, and thirdly in pairs. Students felt that individual presentations were less intimidating and they were able to perform better. Individual student problems were identified and remediated, which positively reinforced the students. One to one interactions with the clinical educator allowed for constructive criticism, advice and guidance.

The individual to group and supervisor presentations were very informative, allowed for communication and was a good learning experience. It was also a good follow up to the case study and also allowed for constructive criticism, advice and guidance.

The paired presentations encouraged team work, allowed sharing of work and improved attention given to patients. The strategy also motivated them and each student received good input from the partner. Allowed for peer socialization and learning. The only problem was that students found it difficult to meet after-hours to discuss the case further. The suggestion was that the pair of students stayed on at the clinical facility for a further 15 minutes to discuss the case.

In summary the formative evaluation was not intimidating

\section{Summative Evaluation}

Students felt that the end of block evaluation was fair and appreciated the feedback and was of the opinion that constructive criticism facilitated learning. Some students felt that they did not have sufficient experience related to the 
condition that they were examined on. Some students carried negative experiences from previous blocks and were fearful of the criticisms encountered in the end of block evaluation. Other students felt that the duration of the final summative examination should be longer.

\section{Organization of the Block}

The students felt that it was well organized and structured with adequate contact time with the clinical educator, a good variety of patients, sufficient patient load for allocated time and with specific goals. Students did not have to share patients. Some students requested more exposure to spinal patients. The transfer of patients from the wards to the gymnasium was time consuming due to poor co-ordination of nursing care and porterage.

\section{Time management}

Clinical time was not wasted because students always had patients to treat for the duration of the clinical slot. Schedules were clear and prevented wastage of time even during formal evaluations. To rehabilitate patients, the students required more time and therefore all patients could not be treated adequately. Some students felt that the six-week block was too long and should be reduced.

\section{Supervision}

This aspect was good and students found it easy to discuss problems. Students were comfortable and were encouraged to speak. The supervisor was always available for advice and correction but not " hovering". The individual attention that was given motivated and encouraged them. Some students required supervision with the treatment of all their patients.

\section{Other aspects}

In their first clinical block, students felt that "they were thrown in at the deep end". But this enabled them to cope. They were able to see progress in patients. The supervisor's knowledge of the syllabus allowed for its integration into the treatments. The supervisor had no preconceived expectations of students and created an environment which was conducive to learning. The attention to detail and concern for students well being and acquisition of knowledge and skills was noted. The goals for the block were achieved.

\section{CONCLUSION}

This study shows that a 12:1 student: clinical instructor ratio can produce good clinical education outcomes in third year students provided that the students were given a clear idea of what the requirements were and the supervisor was always at hand to monitor progress and assist them. However the structure of the clinical education experience did not have a significant effect on the quantitative performance of the students.

Since there is no literature on a 12:1 student: clinical instructor ratio, we cannot compare our results with those of others. Our objective data comparisons are based on block assessments by the academic supervisors. This type of assessment is usually subjective and open to bias in an unstructured format. Subjectivity can be improved by creating many opportunities for evaluations and including other examiners.

It is important to provide the students with a good balance of independent and collaborative experiences. This is required for professional practice as well as clinical productivity. Clinical instructors need to be flexible, because of the need to adapt to changes in activities, different skills levels (Futter, 1986), personalities, schedule changes and unforeseen events throughout the block. Supervisors also need the support of other staff members in understanding the gradual increase in productivity of the student in terms of increasing patient load and competence.

A limitation of this report is the absence of subjective reports by students from the other blocks. Student feedback forms an essential component of clinical education.

The authors recommend more structured prospective research into developing a model for supervising large numbers of students. In addition it is important to determine the most objective means to formatively and summatively assess cognitive, affective and psychomotor outcomes in large groups of students.

\section{REFERENCES}

De Clute J, Ladyshewsky R 1993 Enhancing clinical competence using a collaborative clinical education Model. Physical Therapy 73(10): 683-697

Emery M 1986 Student-staff clinics: creative clinical education during times of constraint. Clinical Management 6(2): $6-10$

Futter M J 1986 The Programme of clinical experience and evaluation employed at the University of Cape Town. South African Journal of Physiotherapy 42(2): 43 - 49

Gandy J S 1988 Fiscal Implications for clinical education. In: Issues in Clinical Education: Present status/ Future needs, p 67. American Physical Therapy Association, Alexandria, Va.

Ladyshewsky R 1993 Clinical teaching and the 2:1 student to clinical instructor ratio. Journal of Physical Therapy Education 7: 31 - 35

Lopopolo R 1984 Financial model to determine the effect of clinical education program on Physical therapy departments. Physical Therapy 64:1396-1402

Tiberius R, Gaiptman B 1985 The supervisorstudent ratio:1:1 vs 2:1. Canadian Journal of Occupational Therapy 52: $179-183$ 